\title{
Establishing of track quality level management system for ballastless track of high-speed railway
}

\author{
J. F. Shen, Y. D. Xu \& H. F. Li \\ Key Laboratory of Road and Traffic Engineering of \\ the Ministry of Education, Tongji University, China
}

\begin{abstract}
With the rapid development of the high-speed railway in China, a great challenge is brought to high-speed railway management departments in view of the high traffic density, short skylight, high demand of track quality, and difficulties in ballastless track maintenance. In order to ensure the safe and smooth running of the high-speed railway system with limited maintenance resources, it is necessary to conduct reasonable assessments and management of the quality of the track. The objective of this study is to propose a comprehensive method to evaluate the track quality considering track geometry condition and track structure condition. Track Quality Level Index (TQLI) is proposed to indicate the track quality with a corresponding calculation formula. A detailed introduction of the classification standard of track quality level is also discussed. This study uses the method of centesimal grade and analytic hierarchy process for nondimensionalization and weight coefficient determination, analyses the sensitivity of the weights with perturbation method, and then modifies the parameter weights according to the results of the sensitivity analysis. Finally, practical effects of the track quality level management system are examined with a case study of the Shanghai-Nanjing intercity high-speed railway in China.
\end{abstract}

Keywords: high-speed railway, ballastless track, maintenance, grade management.

\section{Introduction}

Line quality includes track geometry quality and track structure quality. Existing literature on the geometry quality primarily focused on the peak and average 
management of dynamic geometric irregularity. United States, Canada, Australia, European Railway Research Center, Japan and United Kingdom have established their own track geometry index systems $[1,2]$. Research on evaluation of track geometry quality in China were mainly related to Track Quality Index (TQI), power spectrum for track irregularities, and Generalized Energy Index [3].

In terms of track structure quality, most researches considered roadbed settlement as the main reason for the deterioration of the track structure, and focused on the law of roadbed settlement and deterioration [4, 5]. Javad Sadeghi evaluated ballastless track structure quality based on visual inspection [6].

This study puts forward the new concept of track quality level management, combines with actual observed data from comprehensive monitoring train, locomotive shaking monitor meter, locomotive cab installed monitor meter, and artificial train's vibration detection in management system, establishes an evaluation method which comprehensively considerate track geometry quality and track structure quality, puts forward the Track Quality Level Management Index (TQLI) and classified the line level based on track quality level management. Weights sensitivity analysis for parameters of TQLI is conducted by perturbation method. Distribution ratio and range of values of weights are determined. Finally, practical effects of the track quality level management system are examined with a case study of Shanghai-Nanjing intercity high-speed railway in China, it shows that this method can accurately reflect the weak link of the line, find out the root cause of defect, formulate a targeted maintenance plan, realize the accurate maintenance, effectively solve the problems of where need to maintenance and what need to maintenance.

\section{Methodology}

\subsection{Evaluation method}

\subsubsection{Evaluation index}

TQLI is calculated by considering track geometry quality and track structure quality based on detection data, using Track Geometry Index (TGI) as the index of track geometry quality and Track Structure Index (TSI) as the index of track structure quality.

TGI indicates track geometry quality, such as the parameters of profile, alignment, cross-level, gauge and twist. It is obtained by dynamic detection instruments, such as comprehensive monitoring train, locomotive shaking monitor meter, locomotive cab installed monitor meter.

Introducing the concept of change rate of TQI $\left(R_{T Q I}\right)$ as TQI in some unit sections changes fast. $R_{T Q I}$ is the ratio of variation of TQI in one month $\left(T Q I-T Q I_{0}\right)$ to TQI of last month $\left(T Q I_{0}\right)$, explained in Eq. (1)

$$
R_{T Q I}=\frac{T Q I-T Q I_{0}}{T Q I_{0}} \times 100 \%
$$

A locomotive shaking monitor meter is used to detect vertical and lateral vibration acceleration of the locomotive and EUM body, to realize real-time 
monitoring of track quality, and find out the track quality bad place in the line. The detection period of locomotive shaking monitor meter is short, and it can greatly reduce the probability to miss the track quality bad place.

Locomotive cab installed monitor meter is used to detect vertical and lateral vibration acceleration as a supplementary means, but there is a gap between locomotive cab installed monitor meter and locomotive shaking monitor meter in accuracy and detection period. In order to highlight the impact of the place where human body feel bad, it is also incorporated into the evaluation system.

Especially, artificial train's vibration detection inspects ride state of line by human body. It indicates that the quality of the section is more serious than others where the human body can feel the irregularities, so it helps to highlight these sections where humans feel uncomfortable.

TQI, RTQI, data overrun of seven single parameters (C: left profile, right profile, alignment, left cross-level, right cross-level, gauge and twist), data of locomotive shaking monitor meter $(\mathrm{H})$, data of locomotive cab installed monitor meter (T), data of artificial train's vibration detection $(\mathrm{R})$ are take into account in calculation of TGI by using defect deduction method as shown in Eq. (2)

$$
T G I=100-F\left(T Q I, R_{T Q I}, C, T, R, H\right)
$$

The defect deduction method refers to the methodology of calculating the score of each detection data, and evaluating the quality of line by the score. Full marks is 100 . Firstly, determining the defects of track geometry quality and track structure quality by detection data, and deducting points according to the severity of defects. Secondly, accumulating the point deduction. Finally, calculating score of the line by subtracting the accumulating point deduction from 100 .

As the measurement units of parameters in Eq. (2) are different, a dimensionless method is adopted to deal with parameters, calculate equivalent value of parameters, consider the weight and calculate value $F$ according to centesimal system, explained in Eq. (3)

$$
\begin{gathered}
F=\sum_{i=1}^{p} w_{i} \cdot E_{i} \\
\sum_{i=1}^{p} w_{i}=1
\end{gathered}
$$

where $E_{i}$ : equivalent value of parameter $i$,

$w_{i}$ : weight of parameter $i$

$i=1,2, \ldots \ldots, p ; p$ is number of all parameters, including all kinds of data sources in Eq. (2).

TSI reflects track structure quality, including rail, fastener system, concrete slab in ballastless track of high-speed railway. The paper proposed a ballastless track structure system which includes three subsystems: rail system, fastening system, ballastless bed system.

Calculation formula of evaluation index of each subsystems is in Eq. (5)

$$
(R C I, F C I, U C I)=100-\sum_{i=1}^{m} \sum_{j=1}^{n} w\left(T_{i}, S_{j}\right) K\left(T_{i}, S_{j}\right)
$$


$R C I, F C I, U C I$ are quality indices of rail system, fastening system and ballastless bed system respectively. 100 indicates no failure, $w$ is weight coefficient, $k$ is point deduction relating to the type and level of failure, $T$ indicates failure type, $S$ indicates failure level (excellent, good, medium, failure).

Formula (6) is the calculation formula of TQLI, using percentile scoring method. The bigger the TQLI is, the better the line quality is, $w_{1}, w_{2}$ are the weights of TGI and TSI. Evaluation system of TQLI is shown in Fig. 1.

$$
\begin{gathered}
T Q L I=w_{1} \cdot T G I+w_{2} \cdot T S I \\
w_{1}+w_{2}=1
\end{gathered}
$$

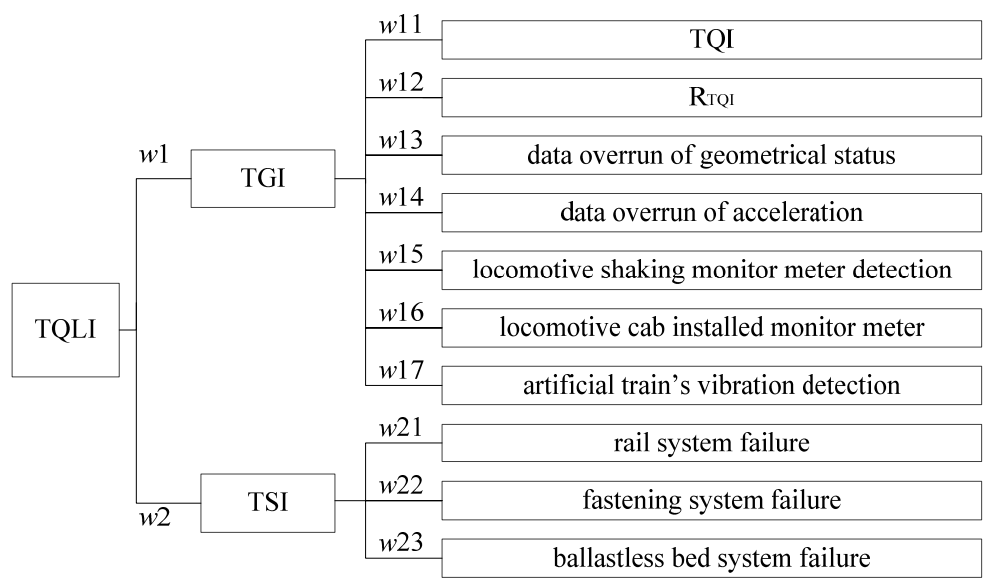

Figure 1: Track quality level management index.

\subsubsection{Level classification standard}

Classifying the sections of line into three levels according to the value of TQLI in order to realize level management. Better quality of the section corresponds to the higher level. A classification standard can be determined by technical parameters of the line and monthly workload arrangement of maintenance team. Table 1 is the classification standard of Shanghai-Nanjing high-speed railway.

Table 1: Level classification standard of section.

\begin{tabular}{c|c|c|c}
\hline Level & Level I & Level II & Level III \\
\hline Value of TQLI & TQLI $\geqslant 95$ & $90 \leqslant$ TQLI $<95$ & TQLI $<90$ \\
\hline
\end{tabular}

\subsection{Thresholds and point deduction standards of parameters}

We should determine thresholds and point deduction standards of parameters (as shown in Figure 1) before calculation equivalent value of point deduction. 


\subsubsection{Data of track geometry status}

Calculation TQI and RTQI of all unit sections in every $200 \mathrm{~m}$, and count the distribution of them. Analyse the relationship between TQI, RTQI and distribution of point deduction compare to point deduction standards of dynamic detection, classify point deduction standards of TQI and RTQI into three levels (as shown in Table 5).

Point deduction standards of data overrun of geometrical status and acceleration refers to Table 2. Point deduction are 10 and 50 for each place where data overrun reach Level I and Level II.

Point deduction Standards of data overrun of locomotive shaking monitor meter and locomotive cab installed monitor meter according to point deduction refer to Table 3. Point deduction are 10,50 and 100 for each place where data overrun reach Level I, Level II and Level III.

Point deduction is 100 when artificial train's vibration detection shows bad, because when human body can feel the irregularities, the quality of this section is so serious.

Table 2: Management value of track dynamic detection of the line with the speed of $250 \mathrm{~km} / \mathrm{h}-350 \mathrm{~km} / \mathrm{h}$.

\begin{tabular}{|c|c|c|c|}
\hline \multicolumn{2}{|c|}{ Level } & Level I & Level II \\
\hline \multirow{2}{*}{\multicolumn{2}{|c|}{ Gauge (mm) }} & +4 & +6 \\
\hline & & -3 & -4 \\
\hline \multicolumn{2}{|c|}{ Alignment (mm) } & 5 & 6 \\
\hline \multicolumn{2}{|c|}{ Twist (mm) } & 4 & 6 \\
\hline Profile $(\mathrm{mm})$ & \multirow{2}{*}{ Wave length $1.5-42 \mathrm{~m}$} & 4 & 6 \\
\hline Cross-level (mm) & & 4 & 5 \\
\hline \multicolumn{2}{|c|}{ Vertical vibration acceleration of vehicle body $\left(\mathrm{m} / \mathrm{s}^{2}\right)$} & 1.0 & 1.5 \\
\hline \multicolumn{2}{|c|}{ Lateral vibration acceleration of vehicle body $\left(\mathrm{m} / \mathrm{s}^{2}\right)$} & 0.6 & 0.9 \\
\hline
\end{tabular}

Table 3: Management value of track dynamic detection instruments.

\begin{tabular}{|c|c|c|c|c|}
\hline Detection instruments & Acceleration $\left(\mathrm{m} / \mathrm{s}^{2}\right)$ & Level I & Level II & Level III \\
\hline \multirow{2}{*}{$\begin{array}{l}\text { Locomotive cab } \\
\text { installed monitor meter }\end{array}$} & $\begin{array}{l}\text { Vertical vibration } \\
\text { acceleration }\end{array}$ & 0.6 & 0.8 & 1.4 \\
\hline & $\begin{array}{l}\text { Lateral vibration } \\
\text { acceleration }\end{array}$ & 0.5 & 0.7 & 1.2 \\
\hline \multirow{2}{*}{$\begin{array}{l}\text { Locomotive shaking } \\
\text { monitor meter }\end{array}$} & $\begin{array}{c}\text { Vertical vibration } \\
\text { acceleration }\end{array}$ & 1.0 & 1.5 & 2.0 \\
\hline & $\begin{array}{l}\text { Lateral vibration } \\
\text { acceleration }\end{array}$ & 0.6 & 1.0 & 1.5 \\
\hline
\end{tabular}

\subsubsection{Data of track structure status}

Point deduction standard of track structure status refers to Table 4. 


\subsection{Weight coefficient determination}

\subsubsection{Initial weight determination}

The Analytic Hierarchy Process (AHP) arranges complex evaluation objects in an orderly hierarchical structure as a whole, pairwise comparison between evaluation parameters, and calculate relative importance coefficients of each parameter, namely the weight. In this paper, steps of initial weight determination are as follows:

(a) Determining quantitative criteria for parameters

Scale is the difference of importance level quantification for parameters, it will influence the rationality of judgment matrix, thereby affecting the results of AHP.

(b) Initial weight determination

Experts should give scores independent of their preference on the relative importance among parameters, and their judgments are averaged to obtain the final score .

(c) Deal with initial weight

(1) Establishing judgment matrix A according to the expert opinion;

(2) Calculating geometric mean of scale data of each row in judgment matrix A, denoted as wi;

(3) Normalized the geometric mean using the formula: $W_{i}{ }^{\prime}=\frac{W_{i}}{\sum W_{i}}$, and determined initial weight according to normalization.

(d) Check for consistency

To check for consistency in the judgments of decision makers, Saaty [7] defined the consistency ratio $(\mathrm{CR})$, which is a comparison of the consistency index (CI) with the random consistency index (RI).

\subsubsection{Weights sensitivity analysis}

Analytic hierarchy process (AHP) is a method that may add more subjective factors. Sensitivity analysis can revise initial weight by calculating effects to evaluation result which cause by weights of parameters change.

Sensitivity analysis generally used perturbation method, namely, make certain conditions for small changes, calculate corresponding changes of output.

\section{Case study}

\subsection{Data source}

Shanghai-Nanjing Intercity High-speed Railway is the busiest railway in China. The running mileage is $301 \mathrm{~km}$, and design speed is $350 \mathrm{~km} / \mathrm{h}$. Slab ballastless track is CRTS I and rail is $60 \mathrm{~kg} / \mathrm{m}$.Selectting K140+000-K290+000 of it as the object of analysis. Geometry data of upline are from comprehensive monitoring train on October, 2013. Geometry data of August and September 2013 are used to calculate $\mathrm{R}_{\mathrm{TQI}}$ and the data of locomotive shaking monitor meter, locomotive cab installed monitor meter, artificial train's vibration detection are from first half year of 2013. Data of the structural state are from Autumn Inspect of 2013, mainly including: rail failure, concrete slab failure and so on. 


\subsection{Track quality level evaluation}

\subsubsection{Thresholds and point deduction standards of TQI}

Distribution of TQI is shown in Figure 2. The value of $3.5 \mathrm{~mm}$ is a turning point, and $41.48 \%$ of TQI are distributed in the interval of $(3,3.5$ ].

Analysis the relationship between TQI and the distribution of point deduction referring to Table 2. Point deduction concentrate on the unit sections that TQI is $3.5-4 \mathrm{~mm}$. In addition, Point deduction concentrate on the unit sections that TQI is $4-5 \mathrm{~mm}$. Therefore, divided point deduction standards into three levels, as shown in Table 5.

Table 4: Point deduction standard of track structure status.

\begin{tabular}{|c|c|c|c|c|c|}
\hline Item & Condition & $\begin{array}{c}\text { Point } \\
\text { deduction }\end{array}$ & Item & Condition & $\begin{array}{c}\text { Point } \\
\text { deduction }\end{array}$ \\
\hline \multirow{2}{*}{ Rail } & $\begin{array}{c}\text { Minor } \\
\text { damage }\end{array}$ & 4 & \multirow{4}{*}{ Sleeper } & Level III failure & 4 \\
\hline & $\begin{array}{l}\text { Severe } \\
\text { damage }\end{array}$ & 20 & & Drop block & 4 \\
\hline \multirow{8}{*}{$\begin{array}{l}\text { Component } \\
\text { missing }\end{array}$} & $\begin{array}{l}\text { Gauge block } \\
\text { missing }\end{array}$ & 16 & & $\begin{array}{l}\text { Plastic casing } \\
\text { failure }\end{array}$ & 4 \\
\hline & $\begin{array}{c}\text { Insulation } \\
\text { gauge block } \\
\text { missing }\end{array}$ & 16 & & $\begin{array}{c}\text { Level III failure } \\
\text { of plastic } \\
\text { extrusion plate }\end{array}$ & 8 \\
\hline & Bolt missing & 16 & \multirow{3}{*}{$\begin{array}{l}\text { Cement } \\
\text { emulsified } \\
\text { asphalt } \\
\text { mortar } \\
\text { layer }\end{array}$} & $\begin{array}{l}\text { Level III failure } \\
\text { of crack }\end{array}$ & 4 \\
\hline & $\begin{array}{l}\text { Bolt casing } \\
\text { missing }\end{array}$ & 4 & & $\begin{array}{l}\text { Level III failure } \\
\text { of gap }\end{array}$ & 8 \\
\hline & $\begin{array}{l}\text { Elastic bar } \\
\text { missing }\end{array}$ & 16 & & $\begin{array}{c}\text { Drop block, } \\
\text { peeling off, } \\
\text { leakage }\end{array}$ & 4 \\
\hline & $\begin{array}{l}\text { Iron plate } \\
\text { missing }\end{array}$ & 16 & \multirow{2}{*}{$\begin{array}{l}\text { Base } \\
\text { plate, } \\
\text { support } \\
\text { layer, } \\
\text { lateral } \\
\text { baffle } \\
\text { block, } \\
\text { convex } \\
\text { block }\end{array}$} & $\begin{array}{l}\text { Level III failure } \\
\text { of crack }\end{array}$ & 4 \\
\hline & $\begin{array}{l}\text { Rail pad } \\
\text { missing }\end{array}$ & 16 & & $\begin{array}{l}\text { Drop block, } \\
\text { peeling off }\end{array}$ & 2 \\
\hline & $\begin{array}{c}\text { Height } \\
\text { adjustment } \\
\text { pad missing }\end{array}$ & 16 & $\begin{array}{l}\text { Drainage } \\
\text { facility }\end{array}$ & No dredging & 1 \\
\hline
\end{tabular}

\subsubsection{Thresholds and point deduction standards of $R_{T Q I}$}

Distribution of $R_{T Q I}$ is shown in Figure 3. 74.52\% of $R_{T Q I}$ distribute below $5 \%$, considering there is an upper bound of monthly workload for the maintenance team, we can only evaluate and maintain the remaining $25.48 \%$ unit sections. In the remaining unit sections, $R_{T Q I}$ which is between $15 \% \sim 15 \%, 5 \% \sim 25 \%$ and 
more than $25 \%$ accounted for $81.91 \%, 14.95 \%$ and $3.14 \%$. Therefore, divided point deduction standards into three levels, as shown in Table 5.

\subsubsection{Thresholds and point deduction standards of locomotive shaking monitor meter and locomotive cab installed monitor meter}

Average number of Level III deviation of locomotive cab installed monitor meter and Level II deviation of locomotive shaking monitor meter for every month (as shown in Table 6).

Therefore, when average number of Level III deviation of locomotive cab installed monitor meter is more than 0.05 , point deduction is 4 , when average number of Level II deviation of locomotive shaking monitor meter is more than 0.06 , point deduction is 1 .

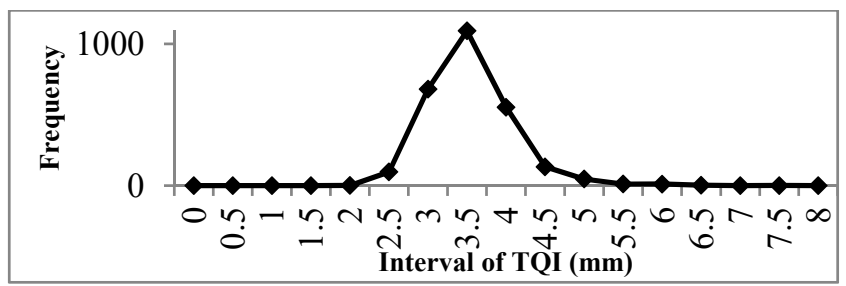

Figure 2: Distribution of tqi in each interval.

Table 5: Thresholds and point deduction standards of tqi and rtqi of unit sections.

\begin{tabular}{c|c|c}
\hline Interval of TQI $(\mathrm{mm})$ & Interval of $R_{T Q I}$ & Point deduction \\
\hline $3.5<\mathrm{TQI} \leq 4$ & $5 \%<R_{T Q I} \leq 15 \%$ & 10 \\
\hline $4<\mathrm{TQI} \leq 5$ & $15 \%<R_{T Q I} \leq 25 \%$ & 50 \\
\hline $\mathrm{TQI}>5$ & $R_{T Q I}>25 \%$ & 100 \\
\hline
\end{tabular}

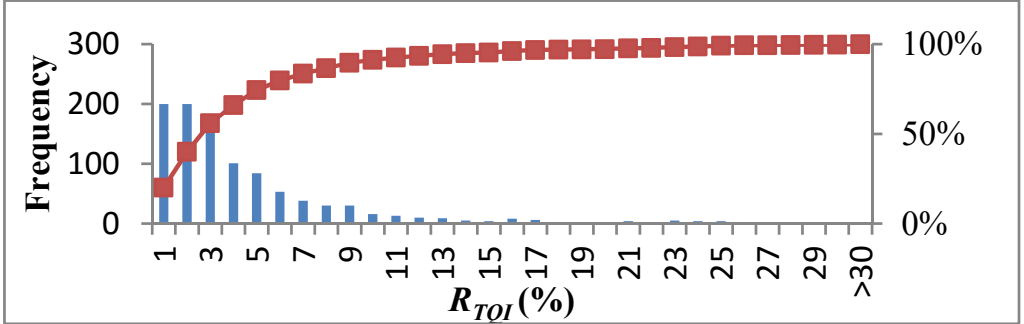

Figure 3: Distribution of rtqi between August and September.

\subsubsection{Calculate the initial weights}

20 experts from the Shanghai Railway Bureau give their judgement for seven parameters of TGI. Integrating views of experts and calculating mean value of 
each element of judgment matrix. The initial weight coefficient of TGI are in Table 8 .

Calculating the weights of subsystems of TSI according to "variable weight model" as shown in Formula (7).

$$
w_{i}=\frac{C I_{i}}{\sum C I}
$$

where $w_{i}$ : weight of parameter $i$;

$C I_{i}$ : value of parameter $i$.

According to the data of Autumn Inspect, weights of each subsystem of TSI of Shanghai-Nanjing intercity high-speed railway are 0.15 for rail system (RCI), 0.05 for fastening systems (FCI) and 0.8 for ballastless bed system (UCI).

Table 6: Average number of deviation in the first half of 2013 (per kilometer).

\begin{tabular}{c|c|c|c|c|c|c|c}
\hline & January & February & March & April & May & June & Average number \\
\hline $\begin{array}{c}\text { Locomotive } \\
\text { shaking monitor } \\
\text { meter }\end{array}$ & 0.048 & 0.054 & 0.056 & 0.062 & 0.047 & 0.045 & 0.052 \\
\hline $\begin{array}{c}\text { Locomotive cab } \\
\text { installed monitor } \\
\text { meter }\end{array}$ & 0.051 & 0.063 & 0.080 & 0.064 & 0.052 & 0.049 & 0.060 \\
\hline
\end{tabular}

\subsubsection{Correction and determination of weights}

The parameters of TGI are divided into three categories: TQI category (TQI, $\left.R_{T Q I}\right)$, data overrun of dynamic detection category (geometric state, acceleration), vehicle detection category (locomotive shaking monitor meter, locomotive cab installed monitor meter, artificial train's vibration detection). Sensitivity analysis is done from inside and outside of these categories.

The perturbation step of weight is 0.05 , calculate TGI with each weight according to Eq. (2), determine the corresponding track quality level, and calculate the number and proportion of different levels of unit sections.

In the case of TQI category inside, when TQI and $R_{T Q I}$ perturbed, the remaining weights of five parameters are unchanged. Percentage of different line levels when TQI weight increase and $R_{T Q I}$ weight decrease are shown in Table 7.

The proportion of level II line and level III line increase and the proportion of level I line decrease when the weight of TQI increase and the weight of $R_{T Q I}$ decrease. When the two weights of TQI and $R_{T Q I}$ are 0.1 , variable quantity of proportion of level I line and level II line reached maximum, respectively, change $5.4 \%$ and $5 \%$.

Theoretically, increased weights of TQI and $R_{T Q I}$ will make the value of corresponding deduction item in Eq. (2) increase and TGI decrease, which may lead to the decrease of proportion of level I line and the increase of proportion of level II line and level III.

Variable trend of level classification will be the opposite caused by weight perturbation of TQI and $R_{T Q I}$ when the total weight of the TQI class is constant.

The weight of $R_{T Q I}$ and proportion of level I line decrease with the increase of the weight of TQI as shown in Table 7. Thus, variable trend of weight of TQI have 
more effect than $R_{T Q I}$ on level classification, and eventually proportion of level I line towards decrease under its influence. In the same way, reasonable ranges of all parameters are obtained, and the initial weights are modified to be corrected as shown in Table 8.

Weight of TSI is determined by objective weighting method, and it is no need to be corrected. Track geometry status and track structure status are equally important in Shanghai-Nanjing intercity high-speed railway, thus, weight ratio of TGI and TSI of TQLI is 1:1.

Table 7: $\quad$ Percentage of different line levels when TQI weight increase and $R_{T Q I}$ weight decrease.

\begin{tabular}{c|c|c|c|c|c}
\hline No. & TQI & $R_{T Q I}$ & Level I (\%) & Level II (\%) & Level III (\%) \\
\hline 1 & 0 & 0.2 & 98.07 & 1.4 & 0.53 \\
\hline 2 & 0.05 & 0.15 & 97.53 & 2.07 & 0.4 \\
\hline 3 & 0.1 & 0.1 & 96.87 & 2.53 & 0.6 \\
\hline 4 & 0.15 & 0.05 & 91.47 & 7.53 & 1 \\
\hline 5 & 0.2 & 0 & 87.73 & 10.53 & 1.73 \\
\hline
\end{tabular}

Table 8: Weight coefficient of track geometry index in the Shanghai-Nanjing intercity high-speed railway.

\begin{tabular}{l|c|c|c|c|c|c|c}
\hline Parameter & TQI & $R_{T Q I}$ & $\begin{array}{c}\text { Data } \\
\text { overrun } \\
\text { of } \\
\text { geometric } \\
\text { state }\end{array}$ & $\begin{array}{c}\text { Data } \\
\text { overrun of } \\
\text { acceleration }\end{array}$ & $\begin{array}{c}\text { Locomotive } \\
\text { cab } \\
\text { installed } \\
\text { monitor } \\
\text { meter }\end{array}$ & $\begin{array}{c}\text { Artificial } \\
\text { train's } \\
\text { vibration } \\
\text { detection }\end{array}$ & $\begin{array}{c}\text { Locomotive } \\
\text { shaking } \\
\text { monitor } \\
\text { meter }\end{array}$ \\
\hline Initial weight & 0.1 & 0.1 & 0.4 & 0.1 & 0.15 & 0.1 & 0.05 \\
\hline $\begin{array}{l}\text { Correction } \\
\text { weight }\end{array}$ & 0.15 & 0.15 & 0.27 & 0.18 & 0.05 & 0.1 & 0.1 \\
\hline
\end{tabular}

\subsubsection{Result of track quality level evaluation}

Line quality of Shanghai-Nanjing intercity high-speed railway in K140+000K290+000 is shown in Table 9.

Table 9: Line quality of the Shanghai-Nanjing intercity high-speed railway.

\begin{tabular}{c|c|c|c|c}
\hline Level & $\begin{array}{c}\text { Number of unit } \\
\text { sections }\end{array}$ & Proportion (\%) & Line length (m) & Proportion (\%) \\
\hline I & 350 & 85.2 & 132300 & 88.2 \\
\hline II & 54 & 13.1 & 16500 & 11.0 \\
\hline III & 7 & 1.7 & 1200 & 0.8 \\
\hline
\end{tabular}


Different management methods are needed for different unit sections:

Level I lines are managed by the Work Area in China. The key work is to maintain on the place where data overrun of locomotive shaking monitor meter is heavy. Pay attention to daily analysis of data overrun of dynamic detection and preventive maintenance.

Level II lines are managed by the Workshop. Strengthening the comprehensive analysis which is combined with static detection for unit sections of Level II line in three consecutive months.

Level III lines are managed by the Track Maintenance Division. The key work is to develop a careful maintenance plan which is combined with static detection for the unit sections of Level III line in last month.

K235+800-K236+000 belongs to Level III line, inspecting and analyzing by the above method and develop a careful maintenance plan (as shown in Table 10). The quality of this section has risen to Level I in the next month after maintenance. This shows that the utilize of track quality level management for ballastless track is feasible.

Table 10: Problem and solution analysis in $\mathrm{k} 235+800-\mathrm{k} 236+000$.

\begin{tabular}{|c|c|c|c|c|c|}
\hline \multirow{5}{*}{ Inspect } & \multicolumn{3}{|c|}{ Geometric state } & \multicolumn{2}{|c|}{ Structure state } \\
\hline & Profile & \multicolumn{2}{|c|}{$\begin{array}{l}>2 \mathrm{~mm} \text { in ten place, }>3 \mathrm{~mm} \text { in } \\
\text { seven place }\end{array}$} & \multirow{2}{*}{ Rail } & \multirow{2}{*}{$\begin{array}{l}\text { Rail failure in } \\
\text { one place }\end{array}$} \\
\hline & Alignment & \multicolumn{2}{|c|}{$\begin{array}{c}>3 \mathrm{~mm} \text { in seven place, }>2.5 \mathrm{~mm} \\
\text { in ten place }\end{array}$} & & \\
\hline & Twist & \multicolumn{2}{|c|}{$\begin{array}{c}>3 \mathrm{~mm} \text { in seven place, }>2.5 \mathrm{~mm} \\
\text { in twelve place }\end{array}$} & \multirow[b]{2}{*}{ Slab } & \multirow{2}{*}{$\begin{array}{l}\text { Slab failure in } \\
\text { one place, } \\
\text { Convex block } \\
\text { failure in one } \\
\text { place }\end{array}$} \\
\hline & Gauge & \multicolumn{2}{|c|}{$>1.5 \mathrm{~mm}$ in one place } & & \\
\hline Analysis & \multicolumn{5}{|c|}{$\begin{array}{l}\text { The transition section between bridge abutment and embankment is a } \\
\text { transition curve }(\mathrm{R}=1000 \mathrm{~m}) \text {, geometric state is affected by geological } \\
\text { condition and easy to change. The score of this section is } 84 \text { and } \\
\text { evaluated as Level III line. }\end{array}$} \\
\hline Solution & \multicolumn{5}{|c|}{$\begin{array}{l}\text { Geometric state: maintain the } 2 \mathrm{~mm} \text { of profile in seventeen place, and } \\
\text { seventeen place of alignment. Structural state: maintain components, } \\
\text { tighten fasteners. }\end{array}$} \\
\hline \multirow{2}{*}{ Evaluation } & \multicolumn{2}{|c|}{ Static review inspect } & \multicolumn{3}{|c|}{$\begin{array}{l}\text { Dynamic level evaluation in the } \\
\text { next month }\end{array}$} \\
\hline & \multicolumn{2}{|c|}{$\begin{array}{l}\text { Structure state is good, no data } \\
\text { overrun of geometric state }\end{array}$} & \multicolumn{3}{|c|}{ Level I } \\
\hline
\end{tabular}

\section{Conclusion}

The main work of this research is outlined below.

(a) A track quality evaluation model comprehensively considering the geometric state and the structural state is established based on the existing detection 
tools in China. Improve the current situation which pay attention to track geometry quality and despise track structure quality by incorporating track structure state into the evaluation system

(b) The results of TQLI involves much numerical calculation and a lot of parameters. This study uses the defect deduction method to realize the nondimensionalization of the parameters, and then determines the thresholds and standards of the parameters according to the analysis of actual observed data.

(c) Weighting method is the main method adopted in this study to calculate TGI and TSI. This study uses the method of AHP to determine the weights of parameters of TGI, analyses the sensitivity of the weights with perturbation method, and then modifies the parameter weights based on actual data of Shanghai-Nanjing Intercity High-speed Railway. Variable weight model is used to obtain the weights of parameters of TSI.

(d) Practices in Shanghai-Nanjing intercity high-speed railway shows that the application of the method of the track quality level management proposed by this research contribute much to optimize the distribution of maintenance resources and improve the efficacy of maintenance.

\section{References}

[1] Javad Sadeghi. Development of railway track geometry indexes based on statistical distribution of geometry data [J]. Journal of Transportation Engineering, American Society of Civil Engineers (ASCE), 136(8): 693-700.

[2] Xu Yude, Li Haifeng, Dai Yuehui. Track Maintenance and Management for Urban Mass. Tongji Press. 2007: 31-33.

[3] Wang Weidong, Liu Jinzhao, Liang Zhimin. Generalized Energy Index for Comprehensively Evaluating the Dynamic Characteristics of Vehicle/Track System. [J]. China Railway Science. 2009, 30(5): 22-27.

[4] Javad Sadeghi, Hossein Askarinejad. Quality condition assessment and determination of effective maintenance activities in railway slab tracks [J]. International Journal of Pavement Engineering, 2012, 13(1): 1-10.

[5] Meier-Hirmer, A. Sené, G. Riboulet, F. Sourget, M. Roussignol. A decision support system for track maintenance [J]. WIT, 2006, 217-226.

[6] Javad Sadeghi, Hossein Askarinejad. Development of track condition assessment model based on visual inspection [J]. Structure and Infrastructure Engineering, 2011, 7(12): 895-905.

[7] Saaty, T. L. Mathematical principles of decision making (Principia mathematica decernendi), RWS, Pittsburgh. 